\title{
RELATION OF VARIATIONS IN MEAN CORPUSCULAR VOLUME TO NUMBER OF RETICULOCYTES IN PERNICIOUS ANEMIA
}

\author{
The Significance of Increased Bone Marrow Activity in \\ Determining the Mean Size of Red Corpescles \\ By M. M. WINTROBE \\ (From the Department of Medicine and the Medical Clinic, Johns Hopkins \\ Unizersity and Hospital, Baltimore)
}

(Received for publication March 29, 1934)

It is well known that the macrocytosis of the red corpuscles in pernicious anemia, is as a whole inversely proportional to the degree of anemia and that, as the anemia decreases the red cells become smaller. In an earlier report (1) it was pointed out that the correlation between the red cell count and the mean volume of the erythrocytes is very close when the anemia is only moderate in degree but that this correlation is not so definite in the more advanced stages of anemia. It was also noted that the decrease in the size of the red corpuscles which follows liver therapy, may be preceded by a temporary increase in the mean volume of the red cells. The cause of this temporary increase in macrocytosis was not considered in any detail but it was observed that, in two cases in which reticulocyte counts were made, the peak of the reticulocyte curve coincided with the maximum value for mean corpuscular volume.

Fitzhugh and Persons (2) noted a brief initial drop in mean red cell diameter in pernicious anemia during treatment and a temporary increase in size following this. Brugsch (3) observed an increase in the mean volume as well as the mean diameter of the red corpuscles which occurred in six patients during the second and third weeks of treatment. The former authors made no attempt to explain the variations in cell diameter, but Brugsch attributed the changes to a decrease of microcyte formation and an increase of macrocytes. He observed, however, that the maximum reticulocyte counts coincided fairly well with the period of greatest increase in cell size.

The observations of these investigators as well as my own earlier studies, were made at infrequent intervals and consequently do not afford adequate information concerning the variations in the size of the red corpuscles. The present more detailed examinations have therefore been carried out. 


\section{OBSERVATIONS}

Mean corpuscular volume has been determined at frequent intervals, usually every third or fourth day and in a number of cases daily. during the course of liver therapy in thirty-two cases of pernicious anemia. The methods employed have been described elsewhere $(\dot{t})$.

In Figure 1. 4, variations in mean corpuscular volume such as were frequently olsserved, are shown. Immediately following the institution of treatment, and sometimes even before therapy was commenced, in a number

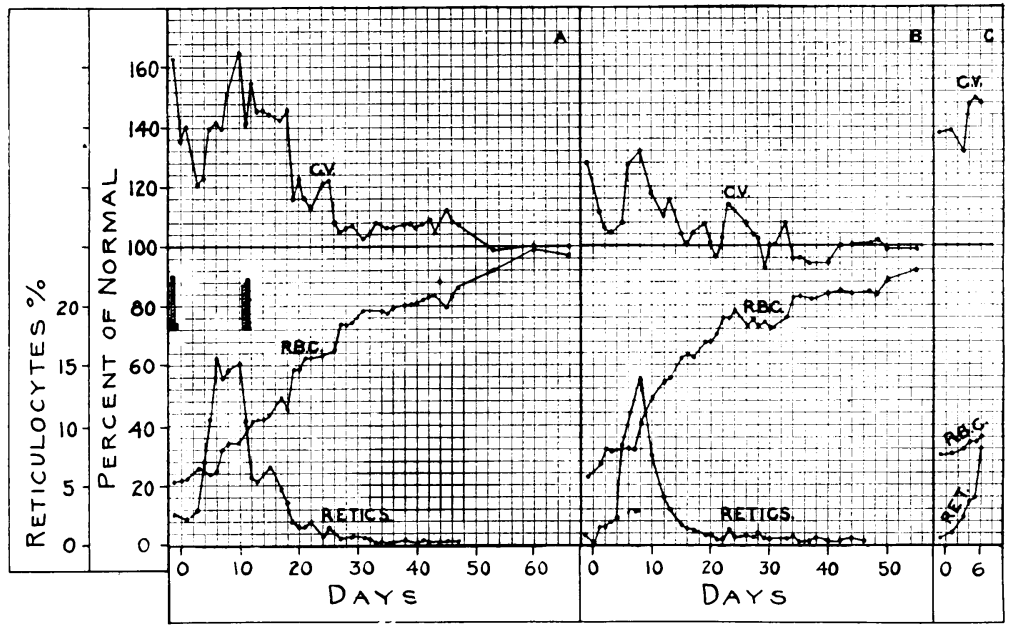

Fig. 1. Variations in Mean Voleme of Reid Corpescles Comparfen with Reticllocyte Cocnt in Thref Cases of Perniciols Anemia

The mean corpuscular volume (C.I.) and the red cell count (R.B.C.) are represented as per cent of their respective average normal values. $B y$ this method the red cell count and mean corpuscular volume of a hypothetical normal individual would fall on the line at 100 per cent. Reticulocrtes are recorded directly. The abscissa records days following the commencement of liver therapy.

The columns represent absolute numbers of red corpuscles 6 microns or less in diameter (hatched columns) and absolute numbers of reticulocytes (solid columns). Each division represents 50,000 cells per c. mm.

of cases there was a decrease in the mean volume of the red corpuscles. Within a few clays, however, there followed an increase in mean corpuscular volume and the maximum attained was in many instances greater than that observed before treatment was instituted. Following this, the volume gradually decreased until finally. when the red count reached normal, normal values for mean corpuscular volume were usually attained.

To this general type of curve there were, however, many exceptions. In a number of cases the preliminary lecrease in mean corpuscular volume was not observed ( see Figures $2, B$, and $3, A$ ). The magnitude of the 
macrocytosis varied and did not appear to be correlated with the degree of anemia alone, although this no doubt is a very important factor (1). The rapidity with which the macrocytosis decreased also differed somewhat in different cases. However, although the form of the "volume curve" varied, it was observed that in 25 instances ( 78 per cent) the decrease in the size of the cells following liver therapy, was preceded by a distinct increase in the size of the red blood cells.

Daily corpuscular volume studies and daily reticulocyte counts were carried out in 9 consecutive cases. The observations are shown in Figures 1,2 , and 3 .

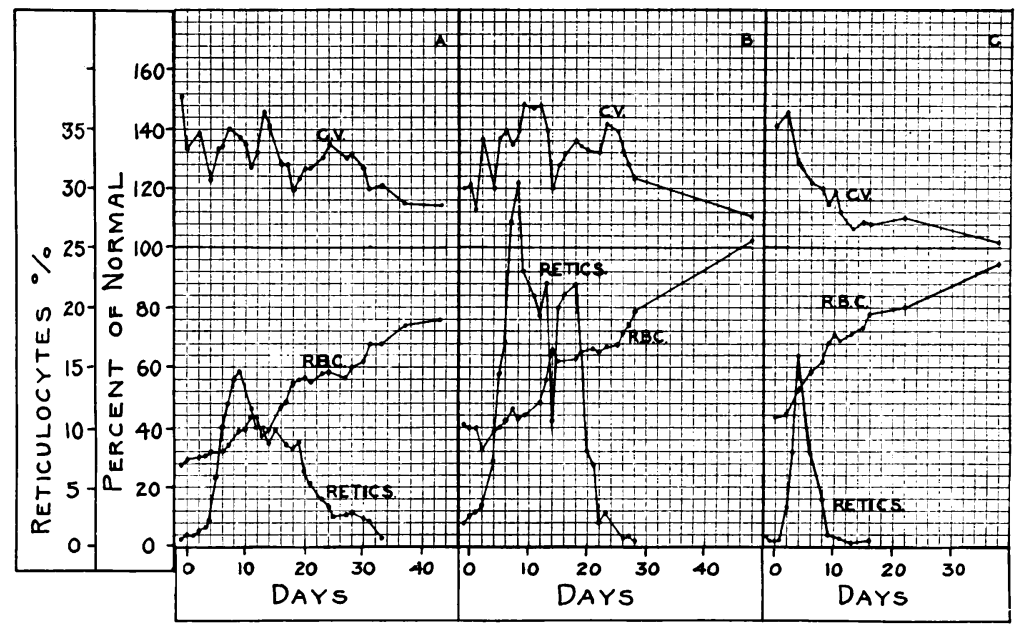

Fig. 2. Variations in Mean Volume of Red Corpuscles Compared with Reticulocyte Count in Three Cases of Pernicious Anemia

Legends same as in Figure 1.

In two instances (Figure $1, A$ and $B$ ) the peak of the increase in corpuscular volume coincided with the peak of the reticulocyte curve. In two cases (Figure 3, $B$ and Figure 2, $A$ ) the maximum increase in volume occurred two and four days, respectively, following the observed maximum increase in reticulocytes. In a fifth case (Figure 2, B) a double peak in the reticulocyte curve was associated with a somewhat similar fluctuation in the volume curve. In this case the peaks of the volume curve followed those of the reticulocyte curve in 2 and in 5 days. In another case (Figure $3, A$ ) the peak in the volume curve followed by 8 days that of the reticulocyte curve. Only a few observations could be made on the patient whose blood changes are shown in Figure 1, $A$.

In only one instance (Figure 2, $C$ ) did the peak of the volume curve precede (by two days) that of the reticulocyte curve. In the ninth patient 
(Figure 3, C) the correlation between the two curves was least eviclent. It is perhaps noteworthy that the anemia in this case was less marked than in any of the other cases and the reticulocyte response to liver therapy was relatively slight.

In the patients whose blood examinations are shown in Figures 1, $A$ and 3,4 , the diameters of the red corpuscles were measured at intervals by means of an ocular micrometer. The alssolute numbers of cells 6 microns or less in diameter, are recorded on the charts and compared with the absolute numbers of reticulocytes. These data indicate that the number of microcytes and small poikilocytes showed relatively little change during the time when reticulocytes and corpuscular volume increased.

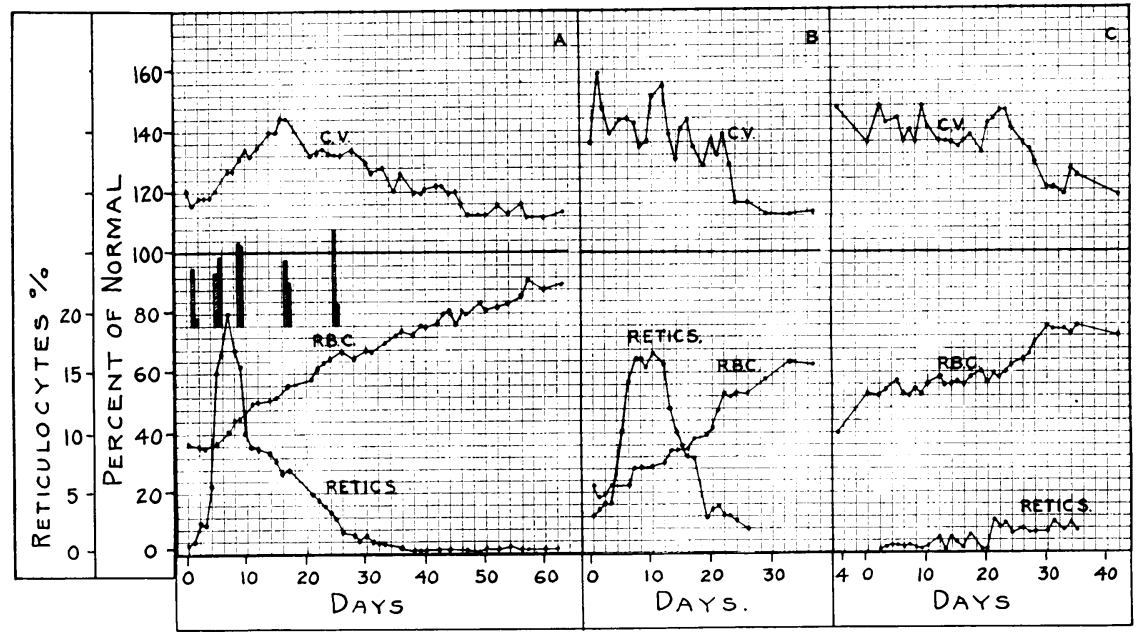

Fig. 3. Variations in Mfax Volleme of Red Corploscles (ompared with

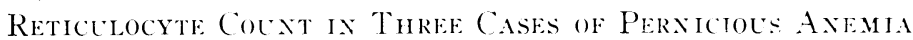

Legends same as in Figure 1.

Icterus index determinations were carried out in each of the nine patients observed daily. In two patients there was a decrease in the icterus index (from 18 to 10, and from 11 to 7.5 , patients of Figure 2. $B$ and Figure $3, A$, respectively) during the first 5 (lays following the institution of treatment, and in one patient (Figure $1, B$ ) the icterus index lecreased from 7.5 to 5 units at the time of the maximum increase in corpuscular volume; during the remaining period of observation in these patients. and during the whole period of observation in the other 6 cases, no consistent tendency of the icterus index either to rise or fall, was notecl.

\section{DISCUSSION}

The data presented inclicate that a preliminary increase in the mean size of the red corpuscles is very frequent in pernicious anemia during liver 
therapy. This serves to explain why the correlation between red cell count and mean corpuscular volume is less marked in the more advanced stages of anemia when the variations in the size of the corpuscles disturb the regular pattern of increasing red cell count and decreasing cell size that is so characteristically seen as treatment becomes effective. The early occurrence of the increased macrocytosis, its close correlation with the reticulocyte curve, and the lack of evidence of significant alterations in the number of microcytes or small poikilocytes, or in the intensity of blood destruction, strongly suggest that the preliminary increase in mean corpuscular volume during liver therapy is due, in great part at least, to the flooding of the circulating blood with immature red corpuscles.

In sprue (1) the writer has observed variations in the volume of the red corpuscles which were similar in every way to those described in pernicious anemia. In these cases there appeared to be the same close parallelism between the augmented macrocytosis and the increase of reticulocytes. In several other (unpublished) cases of non-Addisonian macrocytic anemia an increase in reticulocytes has likewise been associated with an increase in mean corpuscular volume.

Long before the study of reticulocytes had attained the significance it now holds, Biffi (5) and Hawes (6) observed that the majority of reticulocytes are larger than non-reticulated cells in the same preparation. Key (7) confirmed these observations but pointed out that reticulocytes of normal and even of less than normal size may be encountered. More recently this subject has been carefully studied by Persons (8). He demonstrated that in normal blood, in pernicious anemia and in various types of "secondary" anemia, the mean diameter of the reticulocytes is greater than the mean diameter of the adult red cells in the same blood, although the reticulocytes of "secondary" anemia may be actually smaller than normal reticulocytes. In normal blood, reticulocytes were on the average 1 micron greater in diameter than adult corpuscles. In pernicious anemia they were $2.1 \mu$ larger, and in microcytic anemias $0.6 \mu$ larger.

Persons observations are of great importance in the interpretation of variations in the mean volume of the red corpuscles in various types of anemia. If it is presumed for the purpose of discussion that red corpuscles are short cylinders, differences in diameter between reticulocytes and adult corpuscles of the extent noted by Persons are found to correspond approximately to differences of 25 c. $\mu, 64$ c. $\mu$., and 11 c. $\mu$., in the mean volume of immature and adult red cells of normal individuals, and of the average cases of pernicious anemia, and microcytic anemia, respectively. It is obvious, therefore, that it requires the delivery of no very great number of reticulocytes into the circulating blood to produce a significant increase in mean corpuscular volume. Thus it may be calculated that an increase in reticulocytes of 6 per cent (that is, a change from 1 to 7 per cent) would, cacteris paribus, be associated with a rise in the mean corpuscular volume 
from 68 c. $\mu$. to 73 c. $\mu$., in a typical case of microcytic anemia, from 90 to 97 c. $\mu$. in normocytic anemia, and from 106 to 116 c. $\mu$. in a case of pernicious anemia.

The observations in pernicious anemia which have been recorded indicate that increased activity of the bone marrow, as evidenced by an increase of reticulocytes, is actually significant in influencing the mean corpuscular

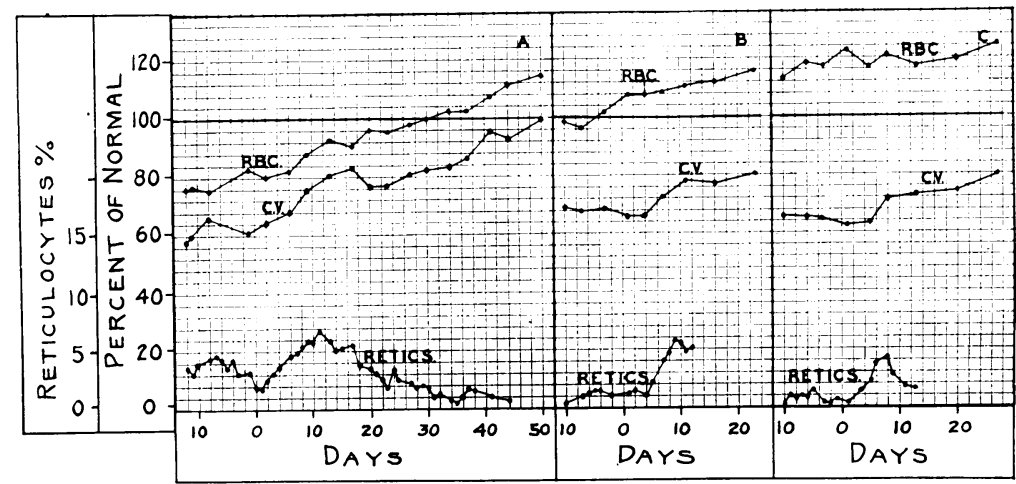

Fig. 4. Imiopathic Hypochromic Anemia. Variations in Mean Volume of Red Corpescles (ompared with Reticulocyte Cocet in Thref. CAsts.

The abscissa records days preceding and following iron therapy. Legends are in other respects the same as in Figure 1.

volume. There can be little (loubt that this is true for other types of anemia as well. In simple microcytic anemia (9) changes in mean corpuscular volume are slight as long as the cause of the anemia persists and the activity of the bone marrow continues to be poor. In hypochromic microcytic anemia, however, the administration of large amounts of iron is associated with a distinct reticulocyte response. In Figure 4 the variations in mean corpuscular volume and reticulocytes in three cases of idliopathic hypochromic anemia are shown. The parallelism between the early and rapid increase in the mean volume of the red corpuscles and the reticulocyte increase in these patients is clear. In a patient with the same type of anemia observed during pregnancy (10) a marked reticulocyte response was associated with a temporary conversion of the microcytic anemia to macrocytic anemia.

It has been pointed out elsewhere (9) that an increase in mean corpuscular volume above normal may occasionally be encountered in cases in which a normocytic type of anemia is usually found ; that is, in anemia due to acute blood loss, acute blood destruction, or lack of blood formation. It has been observed, however. that the macrocytosis which may develop in these cases is not as great as occurs in pernicious anemia and that liver therapy is not followed by the spectacular response which occurs in 
pernicious anemia and sprue. It has been furthermore noted that in such cases, whenever macrocytosis develops there is evidence of unusually increased blood formation. In view of the evidence concerning the relationship of reticulocytosis to increased mean corpuscular volume, it is very probable that the macrocytosis observed in these cases is due to the appearance of immature red corpuscles in great numbers.

A great increase in the activity of the bone marrow with the delivery of a large number of immature erythocytes into the circulation may, then, lead to the development of macrocytic anemia under circumstances in which normocytic anemia is usually encountered. However, the data available do not indicate that the macrocytosis in pernicious anemia is due entirely to the presence of immature red corpuscles as these are generally understood; namely, nucleated red cells and cells containing reticulum, Howell-Jolly bodies, Cabot ring bodies or refractile (Isaacs) granules. The work of Castle, Townsend and Heath (11) and others $(12,13,14,15)$ has demonstrated the relation of a defect in the formation of a "hematopoietic principle" to the development of macrocytic anemia in pernicious anemia, sprue and certain instances of anemia in pregnancy and "tropical" anemia. It is consequently important to distinguish macrocytic anemia which develops as the result of a fundamental disturbance in the mechanism of blood formation from macrocytosis which simply represents a very active response to the sudden loss or destruction of blood, or is associated with the crowding out of immature red corpuscles from the bone marrow by leukemia or new growths.

\section{SUM MARY}

The variations in mean corpuscular volume in cases of pernicious anemia during the response to liver therapy are described.

There is very frequently a temporary increase in macrocytosis following the institution of liver treatment.

This increase in mean corpuscular volume appears to be closely related to the delivery of immature erythrocytes (reticulocytes) into the circulating blood.

The relation of increased activity of the bone marrow to variations in mean corpuscular volume in different types of anemia is considered.

It is suggested that there are two mechanisms by which macrocytic anemia may develop; namely (1) as the result of a defect in the formation of the "hematopoietic principle" of Castle; and (2) by the delivery of large numbers of immature erythrocytes into blood which previously contained red cells of normal size.

I am indebted to J. Walter Landsberg for technical assistance.

\section{BIBLIOGRAPHY}

1. Wintrobe, M. M., The hemoglobin content, volume and thickness of the red blood corpuscle in pernicious anemia and sprue, and the changes associated with liver therapy. Am. J. M. Sc., 1931, 181, 217. 
2. Fitzhugh, G., and Persons, E. L., Studies on red blood cell diameter. IV. The decrease in the mean diameter of the reticulocytes and adult red blood cells in pernicious anemia following liver therapy. J. Clin. Invest., 1929, 7, 631.

3. Brugsch, J. T., Untersuchungen der Wirkung der Leberbehandlung auf die Erythrozytengrössen bei Anaemia gravis. (Anaemia perniciosa.) Folia haemat., 1931, 45, 295.

4. Wintrobe, M. M., Macroscopic examination of the blood. Am. J. M. Sc., 1933, 185, 58.

5. Biffi, U., Eritrociti granulosi di Chauffard-Fiessinger e policromatofilia. Bull. d. sc. med. Bologna, 1908, 8 s., 8, 249. (Quoted by Hawes.)

6. Hawes, J. B., A study of the reticulated red blood corpuscle by means of vital staining methods. Its relation to polychromatophilia and stippling. Boston Med. and Surg. J., 1909, 161, 493.

7. Key, J. A., Studies on erythrocytes with special reference to reticulum, polychromatophilia and mitochondria. Arch. Int. Med., 1921, 28, 511.

8. Persons, E. L., Studies on red blood cell diameter. III. The relative diameter of immature (reticulocytes) and adult red blood cells in health and anemia, especially in pernicious anemia. J. Clin. Invest., 1929, 7, 615.

9. Wintrobe, M. M., The classification and treatment of anemia on the basis of differences in the average volume and hemoglobin content of the red corpuscles. Arch. Int. Med. (In press.)

10. Wintrobe, M. M., and Beebe, R. T., Idiopathic hypochromic anemia. Medicine, 1933, 12, 187.

11. Castle, W. B., Townsend, W. C., and Heath, C. W., Observations on the etiologic relationship of achylia gastrica to pernicious anemia. III. Am. J. M. Sc., 1930, 180, 305.

12. Wills, L., Treatment of "Pernicious Anemia of Pregnancy" and "Tropical Anemia." Brit. Med. J., 1931, 1, 1059.

13. Vaughan, J. M., and Hunter, D., The treatment by marmite of megalocytic hyperchromic anemia. Lancet, 1932, 1, 829.

14. Castle, W. B., and Rhoads, C. P., The aetiology and treatment of sprue in Porto Rico. Lancet, 1932, 1, 1198.

15. Strauss, M. B., and Castle, W. B., Studies of anemia in pregnancy. III. Am. J. M. Sc., 1933, 185, 539. 